\title{
Comments on Lansing and de Vet
}

\author{
John W. Schoenfelder
}

Published online: 1 June 2012

(C) Springer Science+Business Media, LLC 2012

In multiple publications, Lansing has presented his case that Balinese irrigation systems were created and managed largely independent of the state, and that they co-evolved with water temple networks that functioned to control pest levels and water supplies. In this article he and his co-author address skeptics on two fronts: first, those claiming that he's got the ecology wrong, and second, those claiming that he's got the historical anthropology wrong. In my estimation, Lansing and de Vet acquit themselves well on both counts. I won't attempt to be comprehensive in my comments, but I would like to contribute some quick points.

It is fascinating to see the question of the irrigationmanagement role of the polity being argued in part on the basis of interpretations of the Kidung Nderet, which has been described as an "historical song" (Schulte Nordholt 2011: 23) and as a member of "a metrical genre of Balinese literature, rich with metaphors and allusions" (Lansing and de Vet (refer to appropriate page in Lansing and de Vet (this issue))). As someone unable to examine the source for myself, though, it's rather frustrating to see the degree of mismatch between the interpretations of different authors. For example, Schulte Nordholt cites this kidung in support of his statement that a particular son of a king was entitled to impose taxes "with which the upkeep of the dam and tunnel was paid" (2011:23). Lansing and de Vet conclude their section on the kidung by stressing that "the role of the king with respect to irrigation

\footnotetext{
J. W. Schoenfelder $(\square)$

University of Massachusetts Boston,

100 Morrissey Blvd,

Boston, MA, USA

e-mail: schnfldr@ucla.edu

J. W. Schoenfelder

Cotsen Institute of Archaeology at UCLA,

Los Angeles, CA, USA
}

consists in the receipt of taxes" (refer to appropriate page in Lansing and de Vet (this issue)), implying that the taxes were $n o t$ then used to fund irrigation system upkeep. Lansing (pers. comm.) assures me that their discussion focuses on the same incident here referenced by Schulte Nordholt.

If the redistributive expenditures suggested by Schulte Nordholt actually occurred, they would constitute an assistive polity role that went beyond mere extraction. I do not myself have the language skills required to resolve the discrepancy between this reading and Lansing and de Vet's reading of the same kidung. However, from my own experience on Bali I can report that in recent decades groups of farmers have continued to band together to construct new single-subak irrigation systems in mountainous areas. In many other (larger and older) systems, matters of upkeep, repair, crop scheduling, and ritual are handled by autonomous farmer-led organizations with a degree of government involvement that varies, but is often low and sometimes nonexistent. Add to this the current existence of multi-subak water temple or "subak gde" groups, and the overall modern-day situation, as I have observed it, strengthens the plausibility of a past featuring functional groups cohesive enough to carry out larger projects: a past in which large irrigation systems without dynastic involvement are not "unthinkable" (Schulte Nordholt 2011: 27), and that includes "bottom-up" processes of the sorts that Lansing and de Vet draw from the Kidung Nderet and from the writings of van Naerssen and Sorenson.

That said, I actually suspect that pre-colonial royal courts did sometimes make positive contributions to the construction and management of irrigation systems; since the success of these systems could impact both the level of extractable surplus and the legitimacy of taxation, it would be utterly unsurprising if members of the elite occasionally involved themselves in attempts to raise productivity. What is surprising is the dearth of unequivocal evidence of such 
meddling, which I take as evidence that it was at most uncommon, and more likely quite rare. Bali challenges us to ask why apparently available levers of power are sometimes not pulled. In this case, at least part of the answer must lie in the effectiveness of the multi-tiered hierarchy of water temples that today provide physical and institutional venues for cooperative action within and between congregations of farmers. (The top-most tier in the hierarchy is occupied by the temples of Lake Batur and the other central lakes. These often receive a large share of attention, but readers should note that substantive decision-making on matters such as crop scheduling, construction, and system maintenance largely happens at regional, sub-regional, and local levels below the apex, via deliberative processes conducted not by priests, but by subak members and their chosen representatives.)

Inscriptional evidence related to the "Antiquity of the Subaks" section of Lansing and de Vet's paper will be addressed in detail in a forthcoming publication (currently in preparation) by myself and collaborators. In my current estimation, the inscription texts seem consistent with the existence of social organizations equivalent to today's subaks.
By introducing new lines of evidence and providing new readings of hard-to-access historical sources already discussed by others, Lansing and de Vet substantially advance the continuing debate on the nature and relative importance of the roles played by polities, farmers' organizations, and water temples in facilitating agriculture in Bali. This debate, and the authors' position in particular, has been quite productive in illuminating how human power relationships relate to ecological interactions such as those involving crops, pests, and water. It stands as a valuable case study for anyone investigating the interfaces between ecology, production, and social organization.

\section{References}

Schulte Nordholt, N. (2011). Dams and Dynasty, and the Colonial Transformation of Balinese Irrigation Management. Hum Ecol 39:21-27. 